\title{
SUPORTES HÍBRIDOS UTILIZADOS NA IMOBILIZAÇÃO DA PEROXIDASE DE RAIZ FORTE - HRP.
}

\author{
$\underline{\text { Ivan Martins Barreto }}{ }^{1}$; Heiddy Márquez Alvarez ${ }^{2}$; Maria Antônia Carvalho Lima \\ de Jesus ${ }^{3}$ \\ 1. Bolsista PIBIC/CNPq, Graduando em Química, Universidade Estadual de Feira de Santana, e-mail: \\ ivanmarttins@yahoo.com.br \\ 2. Orientador, Departamento de Ciências Exatas, Universidade Estadual de Feira de Santana, e-mail: \\ marquezheiddy@gmail.com \\ 3. Participante do projeto, Departamento de Ciências Exatas, Universidade Estadual de Feira de Santana, e-mail: \\ airamcarvalho@gmail.com
}

PALAVRAS-CHAVE: imobilização; suporte híbrido; HRP.

\section{INTRODUÇÃOO}

A imobilização de enzimas em suportes híbridos mesoporosos (orgânico e inorgânico) atualmente apresenta um grande potencial, devido as melhores características do material quando comparadas a seus componentes separadamente. A síntese destes suportes híbridos pode ser realizada através da funcionalização pós-sintética (enxerto), a co-condensação ou na forma de organosílicas mesoporosas (Adam et al., 2012).

O método da co-condensação utiliza moléculas orgânicas como agentes moldes para a estrutura do material, onde ocorre a condensação do precursor na estrutura. Assim, esse método é bastante utilizado para a obtenção de suportes híbridos de sílica mesoporosos. O processo de imobilização pode ser realizado utilizando diferentes técnicas. Os métodos de adsorção física (ADS) e de ligação covalente (LC) são os mais utilizados. Segundo Singh e colaboradores os métodos por adsorção física e ligação covalente podem reduzir ou evitar a lixiviação da enzima. A enzima pode-se ligar ao suporte orgânico ou inorgânico através de interações adicionais covalentes ou não covalentes, que ocasiona na diminuição da flexibilidade estrutural da enzima e uma maior rigidez a enzima imobilizada, reduzindo a possibilidade de desnaturação (Singh et al., 2013).

A peroxidase de raiz forte ou horseradish peroxidase (HRP) apresenta diversificadas aplicações na indústria, desde a descoloração de corantes sintéticos até 0 desenvolvimento de biossensores (Mohamed et al., 2013), na área clínica e ambiental . Estas possibilidades de aplicação unidas à sua elevada atividade, simplicidade na detecção de produtos e relativa estabilidade leva a desenvolver novos métodos ou suportes que aumentem a estabilidade desta enzima. Suportes inorgânicos de sílicas mesoporosas como, por exemplo, as sílicas SBA-15 e MCF já foram utilizados para a imobilização da HRP com bons resultados (Cao et al., 2013). O objetivo deste trabalho foi desenvolver suportes híbridos que apresentem em sua composição sílica e alginato de sódio com posterior aplicação na imobilização de HRP por ADS e LC.

\section{METODOLOGIA}

\section{Síntese do suporte híbrido de alginato-sílica}

A obtenção dos suportes híbridos foi baseada na metodologia dos suportes das sílicas SBA-15 e MCF (Chouyyok et al., 2009). Usamos o aditivo orgânico alginato de sódio que foi utilizado na proporção de $5 \%(\mathrm{~m} / \mathrm{v})$. Para o preparo dos suportes híbridos de sílica SBA-15, dissolvemos 1,4 g de alginato de sódio em $4 \mathrm{~g}$ de pluronic P127, $30 \mathrm{~g}$ de água destilada e $120 \mathrm{~g}$ de $\mathrm{HCl}(2 \mathrm{M})$. Em seguida, 7,97 g de TEOS. A solução mantevese sob agitação à temperatura ambiente até sua completa homogeneização, em seguida foi aquecida, com refluxo, a $80{ }^{\circ} \mathrm{C}$ durante 24 horas. As partículas obtidas foram 
filtradas e lavadas com água destilada até o $\mathrm{pH}$ neutro. $\mathrm{O}$ material sintetizado foi seco à temperatura ambiente por 24 horas.

Uma parte do suporte obtido foi utilizado diretamente para a imobilização da HRP, outra parte foi direcionada para a impregnação com o sulfato de cobre (II) pentahidratado $\left(\mathrm{CuSO}_{4} .5 \mathrm{H}_{2} \mathrm{O}\right)$ e posterior imobilização da $\mathrm{HRP}$ e uma terceira porção para ser calcinado a $500{ }^{\circ} \mathrm{C}$ durante 6 horas, antes de ser utilizado para a imobilização da HRP. Na impregnação com o $\mathrm{CuSO}_{4} \cdot 5 \mathrm{H}_{2} \mathrm{O}$ utilizamos $5,0 \mathrm{~g}$ do suporte e $20 \mathrm{~mL}$ de uma solução de $\mathrm{CuSO}_{4} .5 \mathrm{H}_{2} \mathrm{O}$ de concentração $0,03 \mathrm{M}$ e $0,3 \mathrm{M}$. A mistura de reação foi mantida sob agitação por 15 minutos num shaker. Após esse período, ocorreu a filtração e secagem do suporte a $60^{\circ} \mathrm{C}$ para posterior imobilização da enzima.

\section{Imobilização da HRP no suporte}

A imobilização da HRP foi conduzida em tampão fosfato $\left(\mathrm{Na}_{2} \mathrm{HPO}_{4} \cdot 2 \mathrm{H}_{2} \mathrm{O}\right) 100 \mathrm{mM} \mathrm{pH}$ 8,0 , meio que propicia maior eficiência de imobilização conforme a literatura. $\mathrm{O}$ efeito do carregamento de HRP no suporte híbrido foi na faixa de 0,125 - $3 \mathrm{mg}$ de $\mathrm{HRP} / \mathrm{g}$ de suporte. O sistema foi mantido sob agitação por 3 horas a $25{ }^{\circ} \mathrm{C}$, em seguida, armazenado a $4{ }^{\circ} \mathrm{C}$ em condição estática, durante 24 horas. Finalmente, o biocatalisador imobilizado foi filtrado e lavado com tampão para retirada de enzimas não adsorvidas e o filtrado foi reservado para quantificação da atividade enzimática.

\section{Determinação da atividade enzimática}

A atividade enzimática da HRP foi determinada por método colorimétrico, baseado na mudança de absorvância a $470 \mathrm{~nm}$ devido à formação do produto de oxidação do guaiacol, o tetraguaiacol durante três minutos ( $\varepsilon$ tetraguaiacol: $\left.26,6 \mathrm{mM}^{-1} \mathrm{~cm}^{-1}\right)(($ Hirata et al., 1998). O ensaio contém 2,76 mL de tampão $\mathrm{Na}_{2} \mathrm{HPO}_{4} \cdot 2 \mathrm{H}_{2} \mathrm{O} 100 \mathrm{mM}(\mathrm{pH} 6,0)$; $0,04 \mathrm{~mL}$ da solução enzimática diluída 200 vezes em tampão $\mathrm{pH} 6,0 ; 0,1 \mathrm{~mL}$ de solução de guaiacol $100 \mathrm{mM}$ e $0,1 \mathrm{~mL}$ de peróxido de hidrogênio $\left(\mathrm{H}_{2} \mathrm{O}_{2}\right) 2,0 \mathrm{mM}$ a $25{ }^{\circ} \mathrm{C}$. Uma unidade de enzima (U) foi definida como a quantidade de enzima capaz de fornecer 1 $\mu \mathrm{mol}$ de produto em 1 minuto a $25^{\circ} \mathrm{C} \mathrm{em} \mathrm{pH} \mathrm{6,0.}$

A eficiência de imobilização (\%) e o número de unidades de enzima imobilizada (U) foram determinados pela diferença entre número de unidades de atividade peroxidásica oferecidas (Uo) e o número de unidades de enzima remanescente no filtrado (Uf), conforme a equação.

$$
\text { Eficiência de imobilização }(\%)=\frac{\left(\mathrm{U}_{\mathrm{o}}-\mathrm{U}_{\mathrm{f}}\right) \times 100}{\mathrm{U}_{\mathrm{o}}}
$$

Os suportes foram caracterizados por técnica de espectroscopia de infravermelho.

\section{RESULTADOS E DISCUSSÃO}

A HRP foi imobilizada por ADS em suporte híbrido alginato-silicato. O efeito da impregnação do íon cobre (II) nos suportes sobre a eficiência de imobilização foi avaliado utilizando duas concentrações do metal $(0,03 \mathrm{M} ; 0,3 \mathrm{M})$.

$\mathrm{O}$ efeito do carregamento de HRP (0,125 - 3,0 $\mathrm{mg}$ de HRP/g de suporte) na imobilização da HRP em suporte híbrido alginato-silicato por ADS é mostrado na Figura 2. 

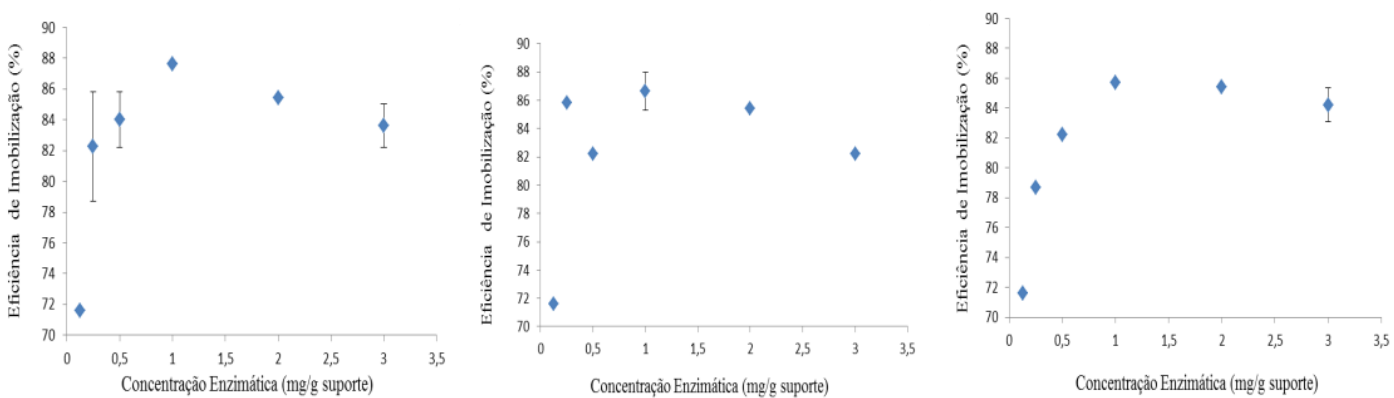

Figura 2: Gráfico da Eficiência de Imobilização da HRP em suporte híbrido alginato-silicato sem calcinar (SH): A) Branco; B) impregnado com o íon $\mathrm{Cu}^{2+}(0,03 \mathrm{M})$; C) impregnado com o íon $\mathrm{Cu}^{2+}(0,3 \mathrm{M})$ As Figuras acima mostram que no método de imobilização por ADS usando o suporte híbrido alginato-silicato, teve um aumento na eficiência de imobilização com o aumento no carregamento no intervalo de 0,125 a $1,0 \mathrm{mg}$ de $\mathrm{HRP} / \mathrm{g}$ de suporte e para um carregamento superior (2,0 e 3,0 mg de $\mathrm{HRP} / \mathrm{g}$ suporte) ocorreu uma diminuição na eficiência. Esse mesmo comportamento pode ser observado para o suporte híbrido alginato-silicato na presença de íons cobre (II). Isso mostra que houve uma afinidade da enzima pelo suporte e essa interação foi proporcional à concentração da enzima. Com os carregamentos (2,0 e 3,0 mg HRP/ g suporte) nota-se uma redução na eficiência de imobilização atribuído provavelmente à sobrecarga de enzima no suporte que leva à limitações difusionais para o substrato (Mohamed et al., 2013). A presença do íon $\mathrm{Cu}^{2+}$ nos suportes não influenciou de forma significativa na eficiência de imobilização.

Gulay e Mohamed (2012) ao imobilizarem esterase em híbrido de sílica e alginato testaram quatro concentrações de enzima $(0,01 ; 0,1 ; 0,5$ e $1 \mathrm{mg} / \mathrm{mL})$ na eficiência de imobilização. A concentração de $0,1 \mathrm{mg} / \mathrm{mL}$ apresentou melhor eficiência $(68,5 \%)$, acima dessa concentração, o suporte em estudo apresentou saturação.

Os resultados mostram que o carregamento de $1,0 \mathrm{mg}$ de HRP/g suporte é considerado ideal para imobilização de HRP por ADS em híbrido alginato-silicato. Os valores para as eficiências de imobilização foram: Branco: (88,8\%); híbrido- Cu (II) 0,03M (88,0\%) e híbrido- $\mathrm{Cu}$ (II) 0,3M (87,2\%).

A enzima HRP também foi imobilizada no suporte híbrido alginato-silicato calcinado (SHC). Os resultados para eficiência de imobilização e a atividade no imobilizado se apresentam na Tabela 1.

Tabela 1: Eficiência de Imobilização da HRP e Atividade Enzimática no Imobilizado em suporte híbrido Alginato/sílica com um carregamento de $10 \mathrm{mg} \mathrm{HRP} / \mathrm{g}$ suporte.

\begin{tabular}{ccc}
\hline Suporte & Eficiência de Imobilização(\%) & Atividade no imobilizado \\
\hline SHC & 57 & $1,8 \times 10^{-4}$ \\
\hline SH & 60 & $1,9 \times 10^{-4}$ \\
\hline
\end{tabular}

De acordo com a Tabela 1, observa-se que o valor para a eficiência de imobilização do híbrido calcinado e sem calcinar foram próximos e bem baixo quando comparado com aos carregamentos estudados anteriormente (0,125mg HRP - $3 \mathrm{mg} \mathrm{HRP/g} \mathrm{suporte).} \mathrm{Isso}$ mostra que muita enzima ficou no filtrado devido a saturação do suporte. Para o carregamento de 10mg HRP/g suporte houve atividade enzimática no imobilizado.

A análise dos espectros de infravermelho dos suportes sintetizados nos ajudou a elucidar as possíveis estruturas destes suportes. Nos espectros de infravermelho se observa a mudança de várias bandas correspondentes à vibração de valência $\mathrm{O}-\mathrm{H}$ e $\mathrm{C}=\mathrm{O}$. O que corrobora a ligação do silicato com as moléculas do alginato através do grupo carboxilato.

Vale lembrar que para a confirmação da estrutura de cada suporte seria necessário a utilização de outro método de caracterização, a saber: difração de raio X (DRX), análise termogravimétrica (TGA) ou microscopia eletrônica de varredura (MEV). Atualmente 
as amostras estão sendo caracterizadas por TGA na Universidade Federal do Rio de Janeiro (UFRJ). Estamos fazendo uma parceria com o instituto de Química da UFBA para realizar as análises de DRX e MEV. Na figura 4, se mostra uma proposta da estrutura dos suportes SH e SHC.

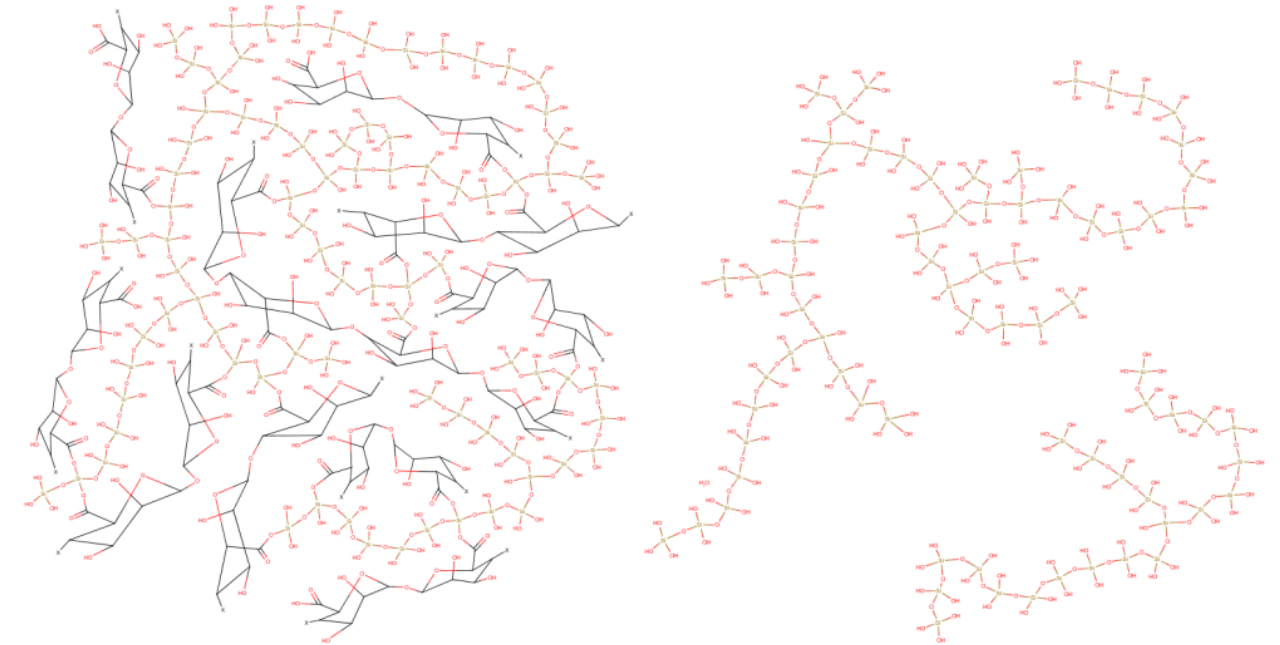

Figura 4: A) Proposta da estrutura do SH. B) Proposta da estrutura do SHC

\section{CONSIDERAÇÕES FINAIS}

A eficiência de imobilização da enzima HRP no suporte híbrido mostrou-se satisfatória. Os valores de eficiência mostraram-se crescentes até o limite de saturação do suporte a partir do qual esses valores começaram a declinar. O carregamento de $1 \mathrm{mg}$ de $\mathrm{HRP} / \mathrm{g}$ suporte foi considerado ideal para imobilização do suporte em estudo. $\mathrm{O}$ íon $\mathrm{Cu}^{2+}$ não influenciou na eficiência de imobilização e na atividade do biocatalisador híbrido. Os biocatalisadores híbridos silicato-alginato não apresentaram atividade enzimática exceto para um carregamento de $10 \mathrm{mg} \mathrm{HRP} / \mathrm{g}$ suporte.

\section{REFERÊNCIAS}

ADAM, F.; APPATURI, J. N.; IQBAL, A. 2012. The utilization of rice husk silica as a catalyst: Review and recent progress, Catalysis Today, 190, p. 2 - 14.

CAO, S; AITA, G.M. 2013. Enzymatic hydrolysis and ethanol yields of combined surfactante and dilute ammonia treated sugarcane bagasse, Bioresource Technology, 131, p. 357-364.

CHOUYYOK, W.; PANPRANOT, J.; THANACHAYANANT, C.; PRICHANONT, S. 2009. Effects of $\mathrm{pH}$ and pore characters of mesoporous silicas on horseradish peroxidase immobilization, Journal of Molecular Catalysis B: Enzymatic, 56, p. 246 252.

GULAY, S.; MOHAMED, G. S. 2012. Immobilization of thermoalkalophilic recombinant esterase enzyme by entrapment in silicate coated $\mathrm{Ca}$-alginate beads and its hydrolytic properties, International Journal of Biological Macromolecules, v. 50, p. 545- 551.

HIRATA, T.; IZUMI, S.; OGURA, M.; YAWATA, T. 1998. Epoxidation of styrenes with the peroxidase from the culture cells of Nicotiana tabacum, Tetrahedron, 54, p. $15993-16003$.

MOHAMED, S.A.; DARWISHA, A.A.; EL-SHISHTAWY, R.M. 2013. Immobilization of horseradish peroxidase on activated wool. Process Biochemistry, v. 48, p. 649 - 655. SINGH, R.K.; TIWARI, M.K.; SINGH, R.; LEE, J. 2013. From Protein Engineering to Immobilization: Promising Strategies for the Upgrade of Industrial Enzymes, International Journal of Molecular Sciences, 14, p. 1232 - 1277. 